Review (57, 546), by Dr. A. O. Nier. Nier there describes fission experiments conducted with small quantities of ${ }^{235} \mathrm{U}$ and ${ }^{238} \mathrm{U}$ separated by deposition in a mass-spectrograph. The masses of ${ }^{238} \mathrm{U}$ samples were of the order of $10^{-7} \mathrm{gm}$. and those of the ${ }^{235} \mathrm{U}$ samples about $10^{-9} \mathrm{gm}$. The samples were bombarded with slow neutrons obtained originally from a cyclotron. Fission products were observed in an ionization chamber when the ${ }^{235} \mathrm{U}$ isotope was used, but not with the more abundant ${ }^{238} \mathrm{U}$. The ${ }^{234} \mathrm{U}$. isotope was not separated from ${ }^{235} \mathrm{U}$, but its abundance is very small. It seems almost certain that ${ }^{235} \mathrm{U}$ is responsible for the slow neutron fission, as predicted theoretically by Bohr and Wheeler.

\section{Shining in Human Eyes}

From time to time, reports have appeared of the occurrence in human eyes of the phenomenon of "night-shining", which as was indicated in a recent paragraph (NATURE, March 30, p. 506) has been observed in many animals by Ernest P. Walker, assistant director of the National Park of the Smithsonian Institution. It was there stated that - Mr. Walker had no definite proof of such cases, although he had encountered reports of them. That statement has led Denis G. A. Dyson, King Edward VI School, Stratford-on-Avon, to write saying that for many years he has known of an "undoubted case" of shining eyes in a shop assistant in Birmingham. Although, not being aware of the rarity of such an occurrence he made no particular observations, his impression is that the glow was of a "dark red colour". In view of the apparent lack of information about such a condition in human beings, it would be of interest if some scientific worker could follow up Mr. Dyson's clue.

\section{War-time Ventilation Problems}

THE question of ventilation is demanding special attention as the warm weather approaches. Mr. A. Peel's article on "War-Time Ventilation", published in the Electrical Times of April 18, is therefore a timely one. Special attention has to be paid to factories, mills, offices, etc., where a large number of people occupy one enclosure. It is an annual problem the solution of which in peace time is not always adopted as soon as it should be. Now certain factors due entirely to the War have greatly aggravated the working conditions in many factories and sometimes added very definite causes of bad ventilation. So far as 'black-out' is concerned, the Government insists that the obscuration must be complete. Whatever form this takes, the blacking-out process is responsible for a marked deterioration compared with the natural ventilation existing before the black-out. Many firms who were obliged hurriedly to arrange their black-out schemes and did so by painting windows or sealing them up by fitting wooden or metal shutters, or in other semi-permanent ways, have already had to strip this material away from windows. This has been necessary in order to get back to something like normal operating conditions as an alternative to serious labour trouble on account of high sickness rates, due to continuous working in artificial light and with poor ventilation.

The proper solution of some of these war-time ventilation problems may involve only the fitting of a small propeller fan or even the opening of all the windows. In other cases it will be essential to use a complete air-conditioning plant whereby a factory or section of a works may operate for twenty-four hours a day all the year round under constant conditions. of temperature and humidity, and with an ample supply of clean fresh air to meet all the requirements of the personnel and of the process carried on. Between these two extremes there will be numerous combinations and modifications of method, and every case has to be studied on its own merits. Complete air-conditioning plant is already in operation in Great Britain in certain sections of the following industries : textiles, printing, biscuit and chocolate manufacture, pharmaceutical chemicals, food manufacture and packing, optical and other fine instrument making, and grinding wheel manufacture. In addition, complete air conditioning is also successfully and economically used for offices and other important rooms. By means of a well-designed plant it is possible to provide in a given space almost any combination of dry bulb temperature and relative humidity. Many different combinations of temperature and humidity are used in practice. Anything which can be done to reduce the variation of heat and moisture load and so cut down the total amount of heat to be dissipated will result in smaller and less costly equipment.

\section{Criminal Anthropology in the U.S.A.}

THe crime wave of appalling dimensions, accompanied by a vast increase in organized crime, which appeared in the United States of America in the years following on the War of 1914-18, continues to constitute one of the gravest of the social problems of State and Federal administration, notwithstanding the repeal of prohibition, which offered an almost unlimited field for illicit gain. In consequence, attention has been directed once more to the possibility of segregating the potential as well as the actual criminal through a method of detection depending upon an anthropometric examination which would weed out or mark down individuals who in their physical characters showed traits characteristic of a criminal type. When crudely stated, this suggests a reversion to the ideas in eriminology held by $\mathbf{C}$. Lombroso in the later years of the last century, which anthropologists believed had been laid to rest when it was shown to general satisfaction that no distinctive criminal type could be said to exist. Nevertheless, a vast survey of criminal anthropology in the United States has been instituted under the ægis of the Division for the Examination of Prisons of the Massachusetts Department of Mental Diseases. It has been carried out by Prof. Earnest A. Hooton of Harvard University, with the assistance of a body of field-workers and statisticians.

The dimensions of the investigation may be gauged from the fact that the case material for native white 